\title{
Atherogenic dyslipidemia and diabetes mellitus: what's new in the management arena?
}

\author{
This article was published in the following Dove Press journal: \\ Vascular Health and Risk Management \\ 24 July 2010 \\ Number of times this article has been viewed
}

\author{
Ajoy Kumar' \\ Vibhuti Singh ${ }^{2}$ \\ 'Bayfront Family Medicine Residency, \\ St Petersburg FL, USA; ${ }^{2}$ University of \\ South Florida College of Medicine \\ and Suncoast Cardiovascular Center, \\ St Petersburg, FL, USA
}

\begin{abstract}
When compared with the general population, the diabetic population is at higher risk of cardiovascular disease (CVD), as predicted by the Framingham Risk Score calculations (10-year risk $20 \%$ ). For this reason diabetes is considered a "coronary disease equivalent" condition, as classified by the National Cholesterol Education Program Adult Treatment Panel (NCEP-ATP) III. Furthermore, patients with diabetes who experience a myocardial infarction have a poorer prognosis than nondiabetic patients, which contributes to their overall higher mortality. Dyslipidemia is a major underlying risk factor contributing to the excess CVD risk, and is usually more atherogenic in the presence of diabetes. It is uniquely manifested by raised levels of triglycerides, low levels of high-density lipoprotein cholesterol, and smaller, denser, and more atherogenic low-density lipoprotein particles. Recent trials have suggested the need for more aggressive treatment of dyslipidemia in this subpopulation than the current recommendations by the NCEP-ATP III. This review addresses the newer developments in the diabetes arena in terms of our current understanding of atherogenic dyslipidemia in diabetes and data from the latest randomized trials addressing its management.
\end{abstract}

Keywords: atherogenic dyslipidemia, diabetes mellitus

\section{Introduction}

The World Health Organization (WHO) defines cardiovascular disease (CVD) as "A group of disorders of the heart and blood vessels and includes coronary heart disease, cerebrovascular disease, peripheral artery disease, rheumatic heart disease, congenital heart disease, deep vein thrombosis, and pulmonary embolism". Furthermore, WHO estimates show that mortality from CVD accounts for $29 \%$ of all deaths worldwide. ${ }^{1}$ In the US, death from CVD continues to be the leading cause of mortality. ${ }^{2}$ More specifically, coronary heart disease (CHD) is the largest component of death related to CVD, both worldwide and within the US. ${ }^{1,2}$ Risk factors for CVD, both major and minor, include high blood pressure, cigarette smoking, high serum cholesterol, low levels of high-density lipoprotein cholesterol (HDL-C), high levels of low-density lipoprotein cholesterol (LDL-C), diabetes, obesity (especially central obesity), left ventricular hypertrophy, family history of premature CVD, and estrogen replacement. ${ }^{3}$

\section{Pathophysiology}

CHD is caused by atherosclerosis, ie, hardening of an artery due to atheromatous plaque. ${ }^{4}$ The formation of an atheromatous plaque, known as atherogenesis, is a complex process involving both cellular and acellular elements. ${ }^{5}$ Although there is a growing body of evidence implicating inflammatory processes and the cells involved
Bayfront Family Medicine Residency,

700 6th Street South, St Petersburg,

FL 3370I USA

Email ajoy.kumar@bayfront.org 
in those processes, the attention of bench and clinical researchers, the pharmaceutical industry, and treatment providers has been focused on acellular elements for several decades. The major acellular elements are cholesterol, cholesterol esters, and phospholipids. Whereas the human body produces the majority of its daily requirement of cholesterol, most Americans now exceed that requirement with additional intake through their diet.

Because cholesterol is insoluble when it enters the circulatory system it is transported as a lipoprotein. The major lipoprotein entities in a fasting individual are LDL-C, HDL-C, and very low-density lipoprotein cholesterol (VLDL-C). Measuring serum fasting lipid levels assists in evaluating and treating excessive serum lipid levels which are associated with increased morbidity and mortality from CHD. A fasting serum lipid panel consists of total cholesterol (TC), LDL-C, HDL-C, and triglyceride concentrations.

While each of the aforementioned parameters have been shown to be independent risk factors for developing CHD, further analysis has shown that the aim of treatment should be reduction of the concentration of LDL-C particles because these are highly atherogenic and constitute $60 \%-70 \%$ of TC. ${ }^{6}$ In fact, the atherogenic nature of LDL-C, even when considered low-risk for developing $\mathrm{CHD}$, has the potential to raise CHD risk, especially when combined with other elements. This overall combination, borderline high-risk LDL-C (130-159 mg/dL), high-normal triglycerides (150-250 mg/dL), presence of small LDL-C particles, and low HDL-C $(<35 \mathrm{mg} / \mathrm{dL})$ is what defines "atherogenic dyslipidemia". ${ }^{7}$ However, as per the Third Report of the National Cholesterol Education Program - Adult Treatment Panel (NCEP-ATP) III, atherogenic dyslipidemia is defined as the triad of elevated triglycerides, low HDL-C, and small LDL-C particles. This triad is most commonly found in individuals with an atherogenic phenotype and/or type 2 diabetes mellitus (DM), and treatment involves lowering triglycerides and increasing HDL-C by diet modification, increased exercise, and pharmacologic therapy with fibrates or nicotinic acid. ${ }^{6}$

\section{Scope of the problem}

The risk of developing atherosclerotic disease is increased two- to three-fold in people with diabetes. ${ }^{9}$ The WHO estimate of worldwide diabetic prevalence of 171 million in 2000 is expected to grow substantially to 366 million by $2030 .{ }^{10}$ In the US alone, the WHO estimates that the prevalence will increase from $17,702,000$ in 2000 to $30,312,000$ by $2030 .{ }^{11}$ For the year 2007, the Centers for Disease Control and
Prevention estimates that the prevalence of diagnosed DM in individuals of all ages in the US was 23.6 million, which is close to the WHO 2030 estimate. DM is categorized as type 1 , type 2 , gestational, and other, with type 2 being the most frequently diagnosed category. ${ }^{12}$ In terms of financial costs, Haung and Basu et al projected that annual spending on DM over the next 25 years will grow to $\$ 336$ billion per year, with Medicare slightly exceeding $50 \%$ of its total yearly expenditure on the disease by $2034 .{ }^{13}$ It is clear that aggressive medical and financial management is needed for type 2 DM and atherogenic dyslipidemia.

\section{Management strategies}

As evidenced by the Scandinavian Simvastatin Survival Study (4S), ${ }^{14}$ Cholesterol And Recurrent Events (CARE), ${ }^{15}$ and Long-Term Intervention with Pravastatin in Ischemic Disease (LIPID) ${ }^{16}$ secondary prevention trials, as well as the primary and secondary trials Heart Protection Study (HPS), ${ }^{17}$ Antihypertensive and Lipid-Lowering Treatment to prevent Heart Attack Trial (ALLHAT), ${ }^{18}$ and Anglo-Scandinavian Cardiac Outcome Trial-Lipid Lowering Arm (ASCOT-LLA), ${ }^{19}$ and the most recent and only primary prevention study, the Collaborative Atorvastatin Diabetes Study (CARDS), ${ }^{20}$ the use of statins in type 2 diabetics has been shown to decrease CVD outcomes significantly (see Figure 1). Furthermore, a meta-analysis of 18,686 diabetics on a statin in the Cholesterol Treatment Trialists' (CTT) collaborators study found that, after a mean follow-up of 4.3 years there was a proportional $9 \%$ decrease in all-cause mortality per $\mathrm{mmol} / \mathrm{L}$ reduction in LDL-C, and a proportional $21 \%$ reduction per $\mathrm{mmol} / \mathrm{L}$ decrease in LDL-C in major vascular events, compared with nondiabetics, indicating that all diabetics should start an HMG-CoA reductase inhibitor if they are at high risk for vascular events. ${ }^{36}$

This is consistent with current treatment recommendations from the NCEP-ATP III, which addresses the management of atherogenic dyslipidemia, and makes recommendations for weight reduction, increased exercise, and lipid-lowering therapies (ie, HMG-CoA reductase inhibitors, fibrates, and nicotinic acid). ${ }^{6}$ In terms of atherogenic dyslipidemia and DM, specifically those with type 2 DM, the NCEP-ATP III and the American Diabetes Association (ADA) both recommend lifestyle modification and $\mathrm{HMG}-\mathrm{CoA}$ reductase inhibitor therapy regardless of baseline LDL-C for those with overt CVD and those without CVD who are age $>40$ years with one or more CVD risk factors. For those who do not have overt CVD or age $<40$ years, statin therapy should be considered, along with lifestyle modification if LDL-C is $>100 \mathrm{mg} / \mathrm{dL}$ or the patient has multiple CVD risk factors. Treatment goals for LDL-C 


\begin{tabular}{|c|c|c|c|}
\hline Study & Intervention & CVD outcome & RRR diabetes \% \\
\hline $\begin{array}{l}\text { Primary prevention } \\
\text { CARDS }\end{array}$ & Atorvastatin $10 \mathrm{mg}$ & $\begin{array}{l}\text { Acute coronary events } \\
\text { CVA }\end{array}$ & $\begin{array}{l}36 \\
48\end{array}$ \\
\hline $\begin{array}{l}\text { Primary and secondary } \\
\text { prevention } \\
\text { HPS }\end{array}$ & Simvastatin $40 \mathrm{mg}$ & $\begin{array}{l}\text { Major CHD event } \\
\text { Any major CV Event }\end{array}$ & $\begin{array}{l}27 \\
22\end{array}$ \\
\hline ALLHAT & Pravastatin $10 \mathrm{mg}$ & Major CHD event & 11 \\
\hline ASCOT-LLA & Atorvastatin $10 \mathrm{mg}$ & $\begin{array}{l}\text { Major CHD event } \\
\text { Total CV events and } \\
\text { procedures }\end{array}$ & $\begin{array}{l}16 \\
23\end{array}$ \\
\hline $\begin{array}{l}\text { Secondary prevention } \\
4 S\end{array}$ & Simvastatin $10-40 \mathrm{mg}$ & $\begin{array}{l}\text { Total mortality } \\
\text { Major CHD event }\end{array}$ & $\begin{array}{l}43 \\
55\end{array}$ \\
\hline CARE & Pravastatin $40 \mathrm{mg}$ & $\begin{array}{l}\text { Major CHD event } \\
\text { Expanded endpoint }\end{array}$ & $\begin{array}{l}13 \\
25\end{array}$ \\
\hline LIPID & Pravastatin $40 \mathrm{mg}$ & $\begin{array}{l}\text { Major CHD event } \\
\text { Any CV event }\end{array}$ & $\begin{array}{l}19 \\
21\end{array}$ \\
\hline
\end{tabular}

Figure I Effect of primary and secondary interventions for type 2 diabetics on CVD outcome.

Notes: Copyright (C) 2006. American Diabetes Association. All rights reserved. Modified with permission from The American Diabetes Association from Solano MP, Goldberg RB. Lipid management from type 2 diabetes. Clin Diabetes. 2006;24(I):27-32.

Abbreviations: 4S, Scandinavian Simvastatin Survival Study; ALLHAT, Antihypertensive and Lipid-Lowering Treatment to prevent Heart Attack Trial; ASCOT-LLA, AngloScandinavian Cardiac Outcome Trial - Lipid Lowering Arm; RRR, relative risk reduction; CARDS, Collaborative Atorvastatin Diabetes Study; CARE, Cholesterol And Recurrent Events; CHD, coronary heart disease; CV, cardiovascular; CVA, cerebrovascular accident; LIPID, Long-Term Intervention with Pravastatin in Ischemic Disease.

are LDL-C $<100 \mathrm{mg} / \mathrm{dL}$ for those without overt CVD, and LDL-C $<70 \mathrm{mg} / \mathrm{dL}$ for those with overt CVD. ${ }^{6,21}$

Non-HDL-C (calculated as total cholesterol - HDL cholesterol) is a secondary target for therapy in the NCEP-ATP III recommendations. The ADA and the American College of Cardiology recommend that non-HDL-C target goals for diabetics with overt CVD should be $<130 \mathrm{mg} / \mathrm{dL}$ and apolipoprotein-B $<80 \mathrm{mg} / \mathrm{dL}$. Those diabetics without overt CVD are recommended to have non-HDL-C $<130 \mathrm{mg} / \mathrm{dL}$ and apolipoprotein-B $<90 \mathrm{mg} / \mathrm{dL} .^{22}$ This is due to the fact that LDL-C is not usually raised in diabetics, thus leaving the components that make up non-HDL-C, especially in the presence of hypertriglyceridemia, more representative and a more reliable measure of atherogenicity, such that there is discussion to advance non-HDL-C as a better predictor of CVD in diabetics. ${ }^{6,23,35}$

Reaching both these current LDL-C and non-HDL-C targets raises the issues of dosage requirements for lipid-lowering drugs, patient tolerability, and side effects either as single or combination treatment. ${ }^{24-26}$ Regardless, in the event that a single statin even at maximal dose is unable to achieve recommended goals, an alternative therapeutic goal is to lower LDL-C by approximately $30 \%-40 \%$ of the baseline value. Should that prove unattainable, consideration should be given to treatment with a combination of medication classes (ie, statin + fibrate). ${ }^{6,21}$ As aforementioned, should the patient also be at high risk for developing vascular events, starting an HMG-CoA reductase inhibitor is beneficial, whilst considering the risks and side effects. Another avenue of diabetic lipid management involves the emerging science behind combining pharmacology and gene regulation.

\section{Newer findings}

Researchers studying adipose tissue as an endocrine organ have identified a number of lipid metabolism regulators. The peroxisome proliferator-activated receptor (PPAR) is a 
nuclear receptor that, when activated, works at the genetic level by regulating lipid and glucose metabolism as well as inflammation. ${ }^{26}$ There are three types of PPARs, ie, PPAR $\alpha$, PPAR $\gamma$, and PPAR $\delta$, all of which are found in organs throughout the body. Fibric acid derivatives (ie, gemfibrozil and fenofibrate) have been used in the treatment of hyperlipidemia. They have also been shown to produce their effects through PPAR $\alpha{ }^{26-29}$ It should be noted that in the Fenofibrate Intervention and Event Lowering in Diabetes (FIELD) study that, compared with placebo, fenofibrates failed to reach statistical significance in reducing the primary study outcome, ie, CHD or nonfatal myocardial infarction, but did show a statistically significant reduction in total cardiovascular events. However there are questions related to the use of statins in the placebo arm. ${ }^{37}$

Thiazolidinediones, which are oral antidiabetic agents, also activate PPAR $\gamma$ and thereby increase adiponectin levels. ${ }^{26,33}$ Increasing adiponectin levels has been shown in animal trials to reduce weight in mice given high-fat diets. ${ }^{30}$ Furthermore, adiponectin has been shown to activate the adenosine monophosphate-protein kinase (AMPK) cascade which regulates energy homeostasis in the body. ${ }^{31}$ The AMPK cascade is also a target for metformin, another oral antidiabetic medication. ${ }^{32}$ Despite these advances in knowledge about the pathophysiology of diabetes, translating this knowledge into clinical practice has been difficult due to drug side effects and increased morbidity. ${ }^{26,33}$

It is also worth mentioning that the recent Bypass Angioplasty Investigation 2 Diabetes (BARI 2D) study found that in 2368 type 2 diabetic patients with heart disease, those with stable ischemic heart disease who received optimal medical management showed no significant disadvantage in terms of the primary endpoint of death or the composite endpoint of death, myocardial infarction, or stroke, compared with those undergoing prompt revascularization only or those with stable ischemic heart disease who underwent delayed revascularization. ${ }^{34}$ These findings have strong implications with respect to cardiac revascularization in type 2 diabetics. However, in terms of primary care, this study shows that optimal medical management of a patient with type 2 diabetes has significant cost benefits without increasing morbidity or mortality, and may become the standard of care in this patient population.

\section{Conclusions}

In summary, the current status, associated cardiovascular risk, expected increase in prevalence, and projected monetary costs associated with DM and atherogenic dyslipidemia are well documented, along with the long-term cardiovascular morbidity and mortality risk. Despite ongoing research, technologic advances, and newer medications that work increasingly at the genetic level, the best and most cost-effective treatment remains prevention. Preventing the development of type $2 \mathrm{DM}$ and its associated cardiometabolic disturbance involves early adoption of a healthy lifestyle that incorporates diet modification, increased exercise, and regular health care maintenance visits with a primary care physician. Once diagnosed, the management involves decreasing the atherogenic components by adherence to the NCEP-ATP III and ADA recommendations, so that the patient and the health system may forestall the ensuing cardiovascular morbidity and mortality, as well as its associated financial burden.

\section{Disclosure}

The authors report no conflict of interest in this research.

\section{References}

1. Cardiovascular diseases (CVDs). Fact sheet No.317. Sep 2009. Geneva: World Health Organization; 2009.

2. American Heart Association. Cardiovascular Disease Statistics. 2010. Available from: http://www.americanheart.org/presenter. jhtml?identifier=4478. Accessed May 20, 2010.

3. Wilson PWF, D'Agostino RB, Levy D, et al. Prediction of coronary heart disease using risk factor categories. Circulation. 1998;97: 1837-1847.

4. Wikipedia. Atherosclerosis. Available from: http://en.wikipedia.org/ wiki/Atherosclerosis. Accessed May 20, 2010.

5. Libby P. Inflammation and the Pathogenesis of Atherothrombotic Disease. Available from: http://www.lipidsonline.org/slides/slide01. $\mathrm{cfm} ? \mathrm{tk}=20 \& \mathrm{pg}=1$. Accessed May 20, 2010.

6. National Cholesterol Education Program. Third report of the expert panel on detection, evaluation, and treatment of high blood cholesterol in adults. Bethesda, MD: National Heart, Lung, and Blood Institute; 2002.

7. Grundy, Scott M. Small LDL, Atherogenic dyslipidemia, and metabolic syndrome. Circulation. 1997;95:1-4.

8. Peters AL. Clinical relevance of non-HDL cholesterol in patients with diabetes. Clin Diabetes. 2008;26:3-7.

9. Kannel, William B, McGee DL. Diabetes and cardiovascular disease: A Framingham study. JAMA. 1979;241:2035-2038.

10. World Health Organization. Diabetes Programme: Country and regional data. Available from: http://www.who.int/diabetes/facts/world_figures/ en/. Accessed May 20, 2010.

11. World Health Organization. Diabetes Programme: WHO region of the Americas. Available from: http://www.who.int/diabetes/facts/ world_figures/en/index3.html. Accessed on May 20, 2010.

12. National Diabetes Fact Sheet: General information and national estimates on diabetes in the United States, 2007. US Department of Health and Human Services: Centers for Disease Control and Prevention; 2008.

13. Huang ES, Basu A, O'Grady M, Capretta JC. Projecting the future of diabetes population size and related costs for the US. Diabetes Care. 2009;32:2225-2229.

14. Haffner SM, Alexander CM, Cook TJ, et al. Reduced coronary events in simvastatin-treated patients with coronary heart disease and diabetes or impaired fasting glucose levels: Subgroup analyses in the Scandinavian Simvastatin Survival Study. Arch Intern Med. 1999;159: 2661-2667. 
15. Goldberg RB, Mellies MJ, Sacks FM, et al. Cardiovascular events and their reduction with pravastatin in diabetic and glucose-intolerant myocardial infarction survivors with average cholesterol levels: Subgroup analysis in the cholesterol and recurrent events (CARE) trial: The CARE Investigators. Circulation. 1998;98:2513-2519.

16. Long-Term Intervention with Pravastatin in Ischemic Disease (LIPID) Study Group: Prevention of cardiovascular events and death with pravastatin in patients with coronary heart disease and a broad range of initial cholesterol levels. N Engl J Med. 1998;339:1349-1357.

17. Collins R, Armitage J, Parish S, Sleigh P, Peto R; Heart Protection Study Collaborative Group. MCR/BHF Heart Protection Study of cholesterollowering with simvastatin in 5,963 people with diabetes: A randomized placebo-controlled trial. Lancet. 2003;361:2005-2016.

18. Major outcomes in moderately hypercholesterolemic, hypertensive patients randomized to pravastatin vs usual care: The Antihypertensive and Lipid-Lowering Treatment to prevent Heart Attack Trial (ALLHAT-LLT). JAMA. 2002;288:2998-3007.

19. Sever PS, Dahlof B, Poulter NR, et al; for the ASCOT investigators. Prevention of coronary and stroke events with atorvastatin in hypertensive subjects who have average or lower-than-average cholesterol concentratons, in the Anglo-Scandinavian Cardiac Outcome Trial - Lipid Lowering Arm (ASCOT-LLA): A multicentre randomized controlled trial. Lancet. 2003;361:1149-1158.

20. Colhoun HM, Betteridge DJ, Durrington PN, et al; The ALLHAT officers and coordinators for the ALLHAT Collaborative Research Group. Primary prevention of cardiovascular disease with atorvastatin in Type 2 diabetes in the Collaborative Atorvastatin Diabetes Study (CARDS): Multicentre randomized placebo-controlled trial. Lancet. 2004;364:685-696.

21. American Diabetes Association. Standards of Medical Care in Diabetes - 2009. Diabetes Care. 2009;32 Suppl 1:S13-S61.

22. Brunzell JD, Davidson M, Furberg CD, et al. Lipoprotein management in patients with cardiometabolic risk: Consensus statement from the American Diabetes Association and the American College of Cardiology Foundation. Diabetes Care. 2008;31:811-822.

23. Grundy SM. Low-density lipoprotein, non-high-density lipoprotein, and apolipoprotein B as targets of lipid-lowering therapy. Circulation. 2002;106: 2526-2529.

24. Kennedy AG, MacLean CD, Littenberg B, et al. The challenge of achieving national cholesterol goals in patients with diabetes. Diabetes Care. 2005;28:1029-1034
25. Nesto RW. LDL cholesterol lowering in Type 2 diabetes: What is the optimum approach. Clin Diabetes. 2008;26:1-6.

26. Staels B, Fruchart J-C. Therapeutic roles of peroxisome proliferatoractivated receptor agonists. Diabetes. 2005;54:2460-2470.

27. Vu-Dac N, Schoonjans K, Kosykh V, et al. Fibrates increase human apolipoprotein A-II expression through activation of the peroxisome proliferator-activated receptor. J Clin Invest. 1995;96:741-750.

28. Vamecq J, Latruffe N. Medical significance of peroxisome proliferatoractivated receptors. Lancet. 1999;354:141-148.

29. Nissen SE, Nicholls SJ, Wolski K, et al. Effects of a potent and selective PPAR- $\alpha$ agonist in patients with atherogenic dyslipidemia or hypercholesterolemia. Two randomized controlled trials. JAMA. 2007;297: 1362-1373.

30. Yamauchi T, Kamon J, Waki H, et al. The fat-derived hormone adiponectin reverses insulin resistance associated with both lipoatrophy and obesity. Nat Med. 2001;7:941-946.

31. Hardie GD, Carling D, Carlson M. The AMP-activated/SNF1 protein kinase subfamily: Metabolic sensors of the eukaryotic cell? Annu Rev Biochem. 1998;67:821-855.

32. Fryer LGD, Parbu-Patel A, Carling D. The anti-diabetic drugs rosiglitazone and metformin stimulate AMP-activated protein kinase through distinct signaling pathways. J Biol Chem. 2002;277:25226-25232.

33. Lincoff MA, Wolski K, Nicholls SJ, Nissen SE. Pioglitazone and risk of cardiovascular events in patient with type 2 diabetes mellitus. A meta-analysis of randomized trials. JAMA. 2007;298:1180-1188.

34. The BARI 2D Study Group. Randomized trial of therapies for Type 2 diabetes and coronary artery disease. N Engl J Med. 2009;360: 2503-2515.

35. Peters AA. Clinical relevance of non-HDL cholesterol in patients with diabetes. Clin Diabetes. 2008;26:3-7.

36. Cholesterol Treatment Trialists' (CTT) Collaborators. Efficacy of cholesterol-lowering therapy in 18,686 people with diabetes in 14 randomised trials of statins: A meta-analysis. Lancet. 2008;371: $117-125$.

37. The FIELD Study Investigators. Effects of long-term fenofibrate therapy on cardiovascular events in 9795 people with type 2 diabetes mellitus (the FIELD study): Randomized controlled trial. Lancet. 2005;366: 1849-1861.
Vascular Health and Risk Management

\section{Publish your work in this journal}

Vascular Health and Risk Management is an international, peerreviewed journal of therapeutics and risk management, focusing on concise rapid reporting of clinical studies on the processes involved in the maintenance of vascular health; the monitoring, prevention and treatment of vascular disease and its sequelae; and the involvement of

\section{Dovepress}

metabolic disorders, particularly diabetes. This journal is indexed on PubMed Central and MedLine. The manuscript management system is completely online and includes a very quick and fair peer-review system, which is all easy to use. Visit http://www.dovepress.com/ testimonials.php to read real quotes from published authors. 